\title{
How early can we diagnose Alzheimer disease (and is it sufficient)?
}

\section{The 2017 Wartenberg lecture}

Ronald C. Petersen, PhD, MD

Neurology ${ }^{\circledR}$ 2018;91:395-402. doi:10.1212/WNL.0000000000006088

\section{Abstract}

A seismic shift in our understanding of the ability to diagnose Alzheimer disease (AD) is occurring. For the last several decades, $\mathrm{AD}$ has been a clinical-pathologic diagnosis, and this conceptualization of the disease has served the field well. Typically, the clinician would identify a syndrome such as mild cognitive impairment or dementia, and label the condition as "probable $\mathrm{AD}$ " since the diagnosis of definite $\mathrm{AD}$ could not be made until an autopsy revealed the presence of amyloid plaques and tau-based neurofibrillary tangles. However, with the advent of biomarkers for $\mathrm{AD}$ including neuroimaging and $\mathrm{CSF}$, the identification of $\mathrm{AD}$ pathology can be made in life, which greatly enhances the ability of clinicians to be precise about the underlying etiology of a clinical syndrome. Hypothetical models of the temporal relation among the pathologic elements and the clinical symptoms have been proposed and have influenced the field enormously. This has enabled clinicians to be specific about the underlying cause of a given clinical syndrome. As such, the diagnostic capability of the clinician is evolving. However, $\mathrm{AD}$ pathology is only a component of the puzzle describing the causes of cognitive changes in aging. Most often, there is a multitude of pathologic entities contributing to the neuropathologic explanation of cognitive changes in aging. $\mathrm{AD}$ changes contribute important elements to the diagnosis, but the final answer is more complex. The field of aging and dementia will have to incorporate these additional elements.

\author{
Correspondence \\ Dr. Petersen \\ peter8@mayo.edu
}

\section{MORE ONLINE}

\section{ค Podcast}

Dr. Jeff Burns interviews

Dr. Ron Petersen about his paper on Alzheimer diagnosis.

NPub.org/q654x0 


\section{Glossary}

AD = Alzheimer disease; DSM-5 = Diagnostic and Statistical Manual of Mental Disorders, 5 th edition IWG $=$ International Work Group; $\mathbf{M C I}=$ mild cognitive impairment; NIA-AA = National Institute on Aging-Alzheimer's Association; PiB = Pittsburgh compound $\mathrm{B} ; \mathbf{R C T}=$ randomized controlled trial; $\mathrm{SCD}=$ subjective cognitive decline.

Alzheimer disease $(\mathrm{AD})$ may be the most devastating disorder of the current generation due to its impact on individuals, families, societies, and health care economies. It is estimated that there are 5.7 million people with $\mathrm{AD}$ in the United States and approximately 46-million worldwide, keeping in mind that, in these figures, $\mathrm{AD}$ and dementia are often conflated. ${ }^{1}$ Nevertheless, these figures are projected to triple by 2030, and $\mathrm{AD} /$ dementia has become the most costly disorder in America, surpassing cancer and cardiovascular diseases. ${ }^{2}$ Therefore, diagnosing and developing therapies for $\mathrm{AD}$ are an absolute necessity.

In order to treat $\mathrm{AD}$, the classification of the disorder must be properly characterized and its natural history understood. Current thinking suggests that by the time clinical symptoms develop, sufficient damage has taken place in the CNS that many symptoms may be irreversible. ${ }^{3}$ As such, early intervention and work toward prevention are preferred strategies. Hence, a complete understanding of the temporal course of the disease is essential, and that understanding is evolving.

\section{History}

In 1906, Alzheimer described a patient, Auguste Deter, who had memory loss and suspiciousness about her family and at autopsy was found to have plaques and tangles in her brain. ${ }^{4}$ In 1968, Blessed et al. ${ }^{5}$ described the association between quantitative measures of dementia and brain pathologic changes. Glenner and Wong ${ }^{6}$ identified the amyloid protein in 1984 as being the major constituent of plaques and Brion et al. ${ }^{7}$ in 1985 identified tau as the major component of neurofibrillary tangles, thus characterizing the molecular substrate of $\mathrm{AD}$. These discoveries laid the groundwork for the current clinical and neuropathologic approaches to the disease. ${ }^{8}$

\section{The problem}

In 1984, the National Institute on Neurological and Communicative Disorders and Stroke and the Alzheimer's Disease and Related Disorders Association criteria were published and set the stage for the conceptualization of $\mathrm{AD}$ for over 30 years. ${ }^{9}$ Essentially, $\mathrm{AD}$ was defined as a clinical-pathologic entity, meaning that, if a person had the gradual onset of a cognitive disorder, usually involving memory, and it led to functional impairment in daily activities, the person would be labeled as having dementia. Once other potential contributing factors had been ruled out, a degenerative disorder was implicated and the label of probable $\mathrm{AD}$ was given. The disorder could only be labeled as definite $\mathrm{AD}$ when the person went on to have an autopsy and, at postmortem examination, the brain showed neuritic plaques (amyloid) and neurofibrillary tangles (tau). Hence, the clinical picture was confirmed, with pathology thus defining the disease. This conceptualization stood for over 30 years and became so well-accepted that the clinical diagnosis of possible/probable $\mathrm{AD}$ was typically shortened to simply AD. Thus, the clinical diagnosis has become equated to the disease process in much of the medical community and the general public. However, problems arose when numerous studies showed elderly cognitively unimpaired persons could have numerous neuritic plaques and neurofibrillary tangles at autopsy, and conversely, people with the clinical picture of probable $\mathrm{AD}$ did not have the defining features of $\mathrm{AD}$ on postmortem examination. ${ }^{10,11}$ The latter finding posed awkward problems for some recent randomized controlled trials (RCTs) showing that up to $10 \%-30 \%$ of APOE4 noncarriers enrolled in a clinical trial for bapineuzumab and solanezumab failed to have amyloid plaques on PET scanning. ${ }^{12,13}$ These features of the 1984 criteria posed a problem for the field, particularly as biomarkers for $\mathrm{AD}$ were evolving.

\section{Enter biomarkers}

Biomarkers reflecting underlying amyloid and tau have been available for 35 years, particularly in the CSF. ${ }^{14}$ Hundreds of studies have shown that, in general, $\mathrm{A} \beta 42$ was decreased and total tau and phosphorylated tau were elevated relative to persons without $\mathrm{AD} .^{14,15}$ While these data have been replicated numerous times, there has been great laboratory-tolaboratory variability in the measurements, such that the results have not been standardized. ${ }^{16}$ In addition, there has been some resistance to lumbar punctures among some patients and clinicians, and consequently, the routine use of CSF for the diagnosis of $\mathrm{AD}$ has not been widely adopted.

In 2004, Klunk et al., ${ }^{17}$ working in Pittsburgh with colleagues from Uppsala, Sweden, demonstrated the utility of the $C^{11}$ PET radioligand, Pittsburgh compound $\mathrm{B}(\mathrm{PiB})$, to identify amyloid plaques in living persons. This changed the landscape dramatically since clinicians no longer had to perform a lumbar puncture or wait for an autopsy to identify the presence of amyloid. ${ }^{17,18}$ While $\mathrm{PiB}$ is a carbon 11 compound with a 20-minute half-life, several fluorine ${ }^{18}$ compounds, florbetapir, flutemetamol, and florbetaben, have been developed and received approval from the US Food and Drug Administration for demonstrating the presence or absence of amyloid in living persons. ${ }^{19}$ This altered the field since the clinical profile coupled with amyloid positivity on PET scan strongly suggested the diagnosis of $\mathrm{AD}$, and RCTs 
could now be designed requiring the presence of amyloid in their study design for an amyloid-targeted therapy. ${ }^{20}$

\section{Theoretical modeling}

With the evolution of biomarkers for $\mathrm{AD}$, Jack et al. ${ }^{21}$ posed a theoretical model of the temporal course and putative role of several pathologic entities and measures antedating the development of clinical symptoms. Figure 1 shows this model with amyloid deposition preceding the development of tau and with subsequent measures of neurodegeneration as measured by with MRI atrophy, such as hippocampal atrophy, cortical thinning, or the presence of hypometabolism in a particular pattern on fluorodeoxyglucose PET. The features of neurodegeneration tended to follow the temporal course of amyloid and tau but with a time lag. All of these events, however, preceded the development of clinical symptoms, such as in mild cognitive impairment (MCI) and dementia. This now classic model has been revised to allow for the subthreshold development of tau preceding detectable amyloid, but otherwise, the essential features of the model have proved accurate and provide the prevailing theoretical picture of $\mathrm{AD} .^{22}$

\section{Criteria}

The development of amyloid imaging and the ability to measure neurodegeneration incorporated in the Jack et al. model led to a proposed set of revisions of $\mathrm{AD}$ criteria, largely for research, in 2011. ${ }^{23-26}$ Figure 2 denotes the progression of criteria and frameworks over the years. The clinical continuum was divided into 3 phases, beginning with the preclinical

Figure 1 Theoretical portrayal of the temporal development of pathologic and clinical events leading to Alzheimer disease dementia

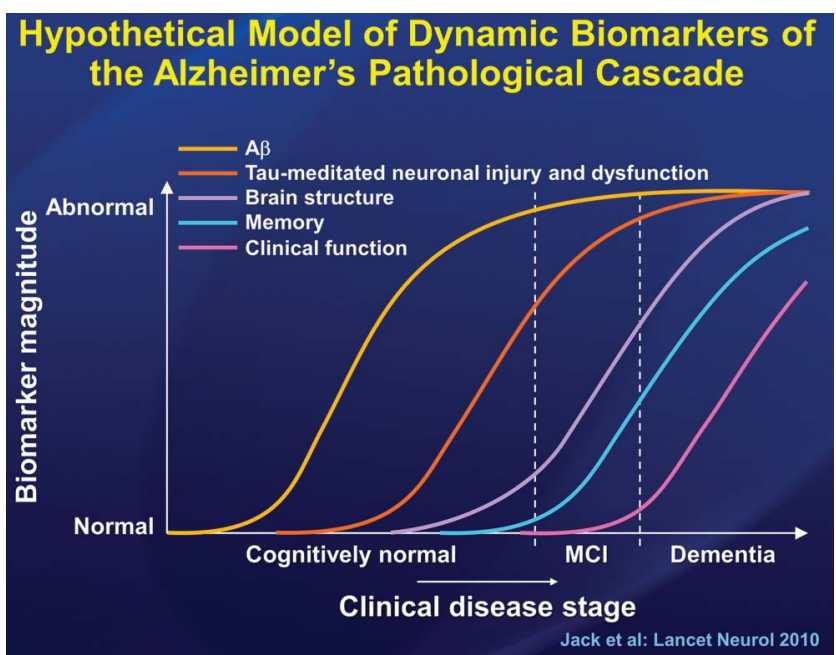

$A \beta=\beta$-amyloid $; C N=$ cognitively normal; $M C I=$ mild cognitive impairment Reproduced with permission from Elsevier. ${ }^{21}$ Copyright (c) 2010 Elsevier Ltd. All rights reserved. state, whereby persons harbored the underlying pathologic features of amyloid deposition and neurodegeneration but were clinically unimpaired. The MCI state denoted individuals with a subtle decline in cognition with preserved function in daily activities, and the final stage constituted dementia. ${ }^{27}$ The clinical criteria for these phases of the $\mathrm{AD}$ clinical continuum were coupled with various combinations of biomarkers denoting the presence of amyloid and neurodegeneration to yield various degrees of likelihood that the underlying clinical syndrome, preclinical (normal cognition), MCI, or dementia, was likely due to $\mathrm{AD}$ pathology. ${ }^{28-30}$ For example, in $\mathrm{MCI}$ due to $\mathrm{AD}$, the first level of certainty involved the clinical syndrome of MCI itself. Next, with various combinations of biomarkers for amyloid and neurodegeneration, the clinical syndrome coupled with these markers increased the confidence of $\mathrm{AD}$ being the underlying etiology. When both measures of amyloid and neurodegeneration were present in conjunction with the clinical syndrome of MCI, the diagnosis of MCI due to $\mathrm{AD}$ with high likelihood was made. This approach was a major advance over the clinical syndrome alone and yielded better results with respect to characterizing a person with the MCI syndrome, estimating the likelihood that person actually possessed the underlying pathophysiology of $\mathrm{AD}$ and predicted the likelihood of cognitive/clinical decline in the future. ${ }^{30-32}$ The design of clinical trials has been profoundly influenced by this advance, combining the clinical criteria with biomarkers.

\section{Other approaches}

Concurrently with the National Institute on AgingAlzheimer's Association (NIA-AA) 2011 criteria development, 2 other efforts have been developed. An International Work Group (IWG) proposed a new conceptualization of $\mathrm{AD}$,

Figure 2 Temporal evolution of criteria and research frameworks for Alzheimer disease

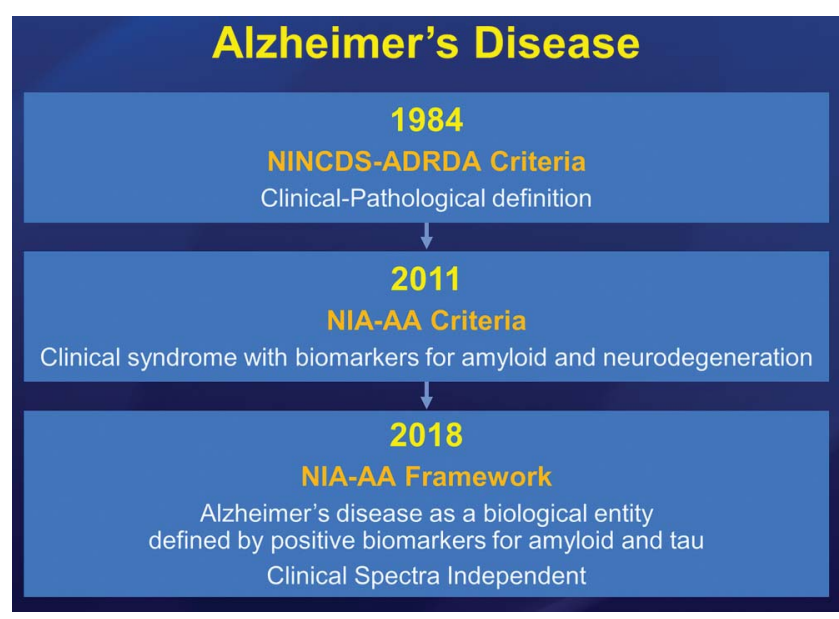

$\mathrm{A} \beta=\beta$-amyloid; $\mathrm{MCl}=$ mild cognitive impairment. Reproduced with permission of Mayo Foundation for Medical Education and Research. All rights reserved. 
building on the clinical syndrome of amnestic MCI and adding amyloid or amyloid and tau biomarkers. ${ }^{33,34}$ At the MCI stage, this was characterized as prodromal $\mathrm{AD}$. In many respects, this characterization of the disease at the predementia stage was similar to MCI due to $\mathrm{AD}$, high likelihood. ${ }^{35}$ This proposal also accommodates atypical clinical presentations of $\mathrm{AD}$.

The American Psychiatric Association published the DSM-5 in 2013, and this classification system used "neurocognitive disorder" as the broad descriptive term, with mild neurocognitive disorder corresponding to $\mathrm{MCI}$ and major neurocognitive disorder resembling dementia. ${ }^{36}$ This approach proposed a 2-step process: fulfillment of the clinical syndrome of mild or major neurocognitive disorder followed by the delineation of the etiology. The latter can be fulfilled by using biomarkers, if available, and in the case of $\mathrm{AD}$, the biomarkers discussed above would be applied when validated. In other disorders, clinical information such as the presence of, e.g., Parkinson disease, Huntington disease, HIV/AIDS, or traumatic brain injury would constitute evidence for etiology of the syndrome. This classification system is meant to encompass many forms of neurocognitive disorders, not just $\mathrm{AD}$. In many respects, both the IWG criteria and DSM-5 are thematically similar to the NIA-AA criteria for $\mathrm{AD}$ with some subtle, but important, differences, as depicted in figure 3 .

\section{New AD framework}

More recently, the NIA-AA empaneled a committee to review the state of the characterization of $\mathrm{AD}$ considering the evolving biomarker data. ${ }^{37}$ Since the 2011 NIA-AA criteria were developed, tau PET imaging has become available, and this, coupled with amyloid imaging, has afforded clinicians the opportunity to detect the presence of the defining neuropathologic features of $\mathrm{AD}$, amyloid and tau, in a living person using imaging. As mentioned above, CSF markers have existed for years but the lack of interlaboratory assay agreement and clinical reluctance to perform lumbar punctures have limited its application in the United States. The development of imaging tools to identify amyloid and tau will likely lead to substantial changes in the manner in which $\mathrm{AD}$ is diagnosed, followed, and treated. ${ }^{38}$

The new $\mathrm{AD}$ framework proposal posits that the term $\mathrm{AD}$ be restricted to persons who have the demonstrated presence of neuritic plaques by either amyloid PET or low CSF A $\beta 42$ and neurofibrillary tangles by tau PET or elevated phospho-tau protein in the CSF. ${ }^{37}$ This means that the disease label can only be given if the person has demonstrated positive biomarkers for amyloid and tau. If the person has only amyloid pathology, then the label of Alzheimer pathologic change should be used. Both of these descriptions, $\mathrm{AD}$ and Alzheimer pathologic change, are independent of the clinical status of the person. That is, a person could be clinically unimpaired, have $\mathrm{MCI}$, or have dementia, since the $\mathrm{AD}$ description is no longer a clinical-pathologic diagnosis. The rationale for this change is partly derived from the parallel with other medical disorders such as cancer and cardiovascular disease. A person can have breast or prostate cancer based on a positive biopsy regardless of the clinical status of the person. Hence, a person will be labeled as having $\mathrm{AD}$ if that person has the biological defining

Figure 3 Interrelations of various criteria for mild cognitive impairment using a combination of clinical features and biomarkers for Alzheimer disease



NIA-AA = National Institute on Aging-Alzheimer's Association; NINCDS-ADRDA = National Institute of Neurological and Communicative Disorders and Stroke-Alzheimer's Disease and Related Disorders Association. Reproduced with permission from Wiley. ${ }^{35}$ Copyright (C 2014 The Association for the Publication of the Journal of Internal Medicine. 
features of the disease, neuritic plaques and neurofibrillary tangles, irrespective of the clinical condition.

It is anticipated that this framework will substantially improve the design of RCTs for $\mathrm{AD}$. Many of the current therapies under development and in current RCTs are targeting amyloid or tau, and this framework will enhance their ability to enroll appropriate participants and follow biologically relevant biomarkers during the course of treatment. This will be a major advancement for the field.

Concerns may arise, however, from the clinician's perspective. The NIA-AA committee recognized the entrenched nature of the term $\mathrm{AD}$ and recommended that when biomarkers are not available, individuals who historically would be labeled possible or probable $\mathrm{AD}$ instead be labeled Alzheimer clinical syndrome. This nomenclature preserves the term $\mathrm{AD}$ in nonbiomarker environments but also recognizes the distinction between a disease and a clinical syndrome that is not specific for any specific disease. Nevertheless, this pathologybased label may more accurately reflect the underlying nature and pathophysiology when someone is labeled as having $\mathrm{AD}$.

\section{Implications for RCTs}

Since much of the focus of developing treatments that will affect $\mathrm{AD}$ currently have been oriented toward early detection of the disease, this new $\mathrm{AD}$ research framework should be useful. Clearly, identifying persons at the early stages of the disease process, prior to the development of symptoms, would be an advantage at preventing subsequent symptom development. ${ }^{39-41}$ Identifying the disease at this stage should allow for early intervention and influence product labeling. Clinical criteria for participant selection would be adjusted accordingly and clinical as well as biomarker outcomes would need to be delineated, but research is underway addressing these issues. Recently, attention has been given to the construct of subjective cognitive decline (SCD) ${ }^{42,43}$ Formerly, it was believed that SCD was simply a manifestation of underlying depression and had little implication for the development of a neurodegenerative process. ${ }^{44}$ However, more recently, several studies have indicated that, after controlling for relevant variables such as age, sex, education, APOE4 carrier status, depression, anxiety, and cognitive function, SCD still predicts progression from cognitively unimpaired to MCI. ${ }^{45}$ In addition, some studies have shown that SCD correlates with underlying biomarker status such as the presence of amyloid on PET imaging in asymptomatic persons. ${ }^{46}$

\section{Clinical syndromes and staging}

While the focus of the new $\mathrm{AD}$ framework has been on biomarkers, the clinical spectrum has been addressed as well, albeit not as part of the definition of $\mathrm{AD}$. The Work Group has recognized 2 approaches to the clinical continuum. An initial description of the classical syndromes is retained- cognitively unimpaired, MCI, and dementia — using standard published criteria. ${ }^{27,36}$ In addition, a numerical staging system has been proposed to enhance the development of RCTs. Stages 1 and 2 refer to degrees of unimpaired cognitive function, with stage 1 being cognitively normal and stage 2 referring to overall normal cognition but subtle signs of early impairment including SCD, slight cognitive changes while still in the normal range, the onset of new neurobehavioral symptoms, or combinations of these features. The specificity of these entities is left purposefully vague to allow research to further delineate these clinical features. Stage 3 approximates MCI and stages 4, 5, and 6 correspond to mild, moderate, and severe dementia. It should be noted that these stages only refer to people who have the demonstrated presence of amyloid and are thus on the $\mathrm{AD}$ continuum. Figure 4 characterizes the correspondences between the clinical syndromes and the proposed staging scheme.

With this background, SCD has become a component in the NIA-AA theoretical depiction of the progression of stages in amyloid-positive persons designed to be used in RCTs. In the clinical staging system proposed for RCTs, stage 2 represents a transitional phase that is used to characterize persons who are cognitively unimpaired but are exhibiting slight changes in cognition, behavior, or subjective concerns. There are several ways to characterize these persons in stage 2, but SCD alone constitutes one of the qualifying features. This presents new challenges for the field in terms of defining the earliest stages of impairment due to underlying $\mathrm{AD}$. Nevertheless, it moves the threshold for initiating therapies further back toward asymptomatic states.

\section{Reality}

Ultimately, aging and cognitive impairment are much more complex than just involving the pathology of $\mathrm{AD}$. While $\mathrm{AD}$ defined by neuritic plaques and neurofibrillary tangles is an

Figure 4 Correspondence of clinical syndromes and stages for Alzheimer disease (AD) in the National Institute on Aging-Alzheimer's Association research framework



$A \beta=\beta$-amyloid; DSM-5 = Diagnostic and Statistical Manual of Mental Disorders, 5th edition; $\mathrm{MCl}=$ mild cognitive impairment. Reproduced with permission of Mayo Foundation for Medical Education and Research. All rights reserved. 
important contributor to cognitive decline in aging, it is not alone. $^{47}$ Typically, when a person older than 70 years is cognitively impaired to some degree, dies, and has an autopsy, multifactorial pathologic changes are the rule. ${ }^{48,49}$ Numerous studies have shown that, while amyloid increases with age, it may plateau toward the later stages of life. ${ }^{50,51}$ Tau accumulation may continue throughout life while other pathophysiologic processes such as TDP-43 continue to increase. ${ }^{52}$ $\alpha$-Synuclein is a common accompaniment of $\mathrm{AD}$ pathogenesis and likely contributes to morbidity as well. ${ }^{53}$ Finally, vascular pathophysiology continues to increase throughout the lifespan, and its role in affecting cognitive function is welldocumented. $^{54-56}$

Figure 5 characterizes this process with the inner core representing the cognitive function continuum. The next ring of concentric circles illustrates the multiplicity of pathologic entities that likely affect cognition. The field is rapidly developing biomarkers for each of these pathologic elements, and those for amyloid and tau are reasonably well-developed, while markers for $\alpha$-synuclein and TDP-43 are under development. Biomarkers for vascular disease, as determined by MRI, are reasonably well-appreciated and are continuing to evolve, as well. This oversimplification does not mean to minimize the complexity of issues involved in the determination of these

Figure 5 Clinical spectrum of cognitively unimpaired-mild cognitive impairment-dementia with its multiple potential etiologies



The contribution of Alzheimer disease (AD) is expressed by $\beta$-amyloid $(A \beta)$ and tau. However, the other protein abnormalities, including TDP-43 and a-synuclein, as well as vascular disease may also contribute to cognitive impairment. The ring of yellow symbols indicates the biomarkers that exist or are being developed for each pathologic entity. Ultimately, treatments will developed for each pathologic component based on its biomarker. Reproduced with permission of Mayo Foundation for Medical Education and Research. All rights reserved. biomarkers including measurement techniques, thresholds for normality, interactions, and other unrecognized contributing factors such as inflammation. Nevertheless, one could envision a scenario whereby a cognitively impaired person would have an array of biomarker tests performed to characterize the underlying pathologic profile contributing to the degree of cognitive impairment. Finally, as therapies are developed for each of these pathologic components, a treatment regimen comprising combination therapies will be tailored for each person. This type of an approach is already being used in disorders such as hypertension, cancer, and HIV/AIDS.

From this perspective, $\mathrm{AD}$ is an important component but only one component in the complex contribution to cognitive function in aging. Figure 5 outlines the $\mathrm{AD}$ component, and one wonders if this component may lose some of its significance as biomarkers are developed for the other pathologic entities. However, for now $\mathrm{AD}$ is a useful construct for political and advocacy purposes and allows communication among physicians, patients, families, and scientists. In the future, it may be just a fraction of the total pathologic picture in cognition and aging, and may best be referred to as the Alzheimer component.

\section{Returning to the question: How early can we diagnose $\mathrm{AD}$ ?}

With all of these accomplishments in the field, the answer to the primary question of "How early can we diagnose $\mathrm{AD}$ ?" is complex. From a clinical perspective, we have made large advancements in our ability to detect the earliest clinical features of the disease, for example, through the recognition of the construct $\mathrm{MCI}^{27} \mathrm{~A}$ recent practice guideline from the American Academy of Neurology has characterized the prevalence of MCI, its likely trajectory, and the current state of interventions. ${ }^{57}$ This has enabled clinicians to counsel patients appropriately, encouraging them to engage in lifestyle modifications, and suggest enrollment in RCTs. The construct of MCI, not without its challenges, has moved the diagnostic threshold earlier in the disease continuum, opening opportunities for research on early intervention in symptomatic disease. However, as outlined above, if the new $\mathrm{AD}$ research framework proposes that the disease be defined by the presence of $\mathrm{AD}$ biomarkers, then the diagnostic process will change. A person would need to have imaging or CSF biomarkers performed to receive the diagnosis of $\mathrm{AD}$ irrespective of clinical state.

From a practical perspective of the clinician, and since the $\mathrm{AD}$ framework is strictly for research at this point, it seems that the utilization of current clinical syndromic criteria for unimpaired cognition, MCI, and dementia will persist, and biomarkers can be used to inform the clinician and patient on the likely underlying etiology of the syndrome. As the field evolves, all this may change, but it is likely to take years before the $\mathrm{AD}$ framework is validated, and it is likely to undergo 
many alterations during that timeframe. Ultimately, our goal is to identify the disease processes as early as possible and intervene with appropriate therapies to eliminate or reduce subsequent damage to the CNS and corresponding symptoms.

\section{Author contributions}

RCP: design and conceptualization of the study, analysis and interpretation of the data, and drafting and revising the manuscript for intellectual content.

\section{Acknowledgment}

Dr. Petersen thanks Clifford R. Jack, Jr., MD, for comments and David Cahill and Samantha Zuk for support.

\section{Study funding}

Dr. Petersen's research is supported by grants from the National Institute on Aging, NIA P50 AG016574, U01 AG006786, U01 AG024904, and the GHR Foundation, Alexander Family Foundation, and the Mayo Foundation for Medical Education and Research.

\section{Disclosure}

R. Petersen consults for Roche, Inc., Merck, Inc., Genentech, Inc., and Biogen, Inc., GE Healthcare, and receives royalties from Oxford University Press for the publication of Mild Cognitive Impairment. Go to Neurology.org/ $\mathrm{N}$ for full disclosures.

Received March 12, 2018. Accepted in final form May 23, 2018.

\section{References}

1. Alzheimer's Association. 2018 Alzheimer's Disease Facts and Figures. Alzheimers Dement 2018;14:367-429.

2. Hurd MD, Martorell P, Delavande A, Mullen KJ, Langa KM. Monetary costs of dementia in the United States. N Engl J Med 2013;368:1326-1334.

3. Sperling RA, Jack CR Jr, Aisen PS. Testing the right target and right drug at the right stage. Sci Transl Med 2011;3:111 cm133.

4. Alzheimer A. Uber eigenartige Krankheitsfalle des spateren Alters [in German]. Zeitscrift Gesamte Neurologie Psychiatrie 1911;4:356-385.

5. Blessed $\mathrm{G}$, Tomlinson BE, Roth $\mathrm{M}$. The association between quantitative measures of dementia and of senile change in the cerebral grey matter of elderly subjects. Br J Psychiatry 1968;114:797-811.

6. Glenner GG, Wong CW. Alzheimer's disease: initial report of the purification and characterization of a novel cerebrovascular amyloid protein. Biochem Biophys Res Commun 1984;120:885-890.

7. Brion JP, Passareiro H, Nunez J, Flament-Durand J. Mise en évidence immunologique de la protéine tau au niveau des lésions de dégénérescence neurofibrillaire de la maladie d'Alzheimer [in French]. Arch Biol 1985;95:229-235.

8. Hyman BT, Phelps CH, Beach TG, et al. National Institute on Aging-Alzheimer's Association guidelines for the neuropathologic assessment of Alzheimer's disease. Alzheimers Dement 2012;8:1-13.

9. McKhann G, Drachman D, Folstein M, Katzman R, Price D, Stadlan EM. Clinical diagnosis of Alzheimer's disease: report of the NINCDS-ADRDA work group under the auspices of Department of Health and Human Services Task Force on Alzheimer's disease. Neurology 1984;34:939-944.

10. Nelson PT, Alafuzoff I, Bigio EH, et al. Correlation of Alzheimer disease neuropathologic changes with cognitive status: a review of the literature. J Neuropathol Exp Neurol 2012;71:362-381.

11. Nelson PT, Head E, Schmitt FA, et al. Alzheimer's disease is not "brain aging": neuropathological, genetic, and epidemiological human studies. Acta Neuropatho 2011;121:571-587.

12. Salloway S, Sperling R, Fox NC, et al. Two phase 3 trials of bapineuzumab in mild-tomoderate Alzheimer's disease. N Engl J Med 2014;370:322-333.

13. Doody RS, Thomas RG, Farlow M, et al. Phase 3 trials of solanezumab for mild-tomoderate Alzheimer's disease. N Engl J Med 2014;370:311-321.

14. Mattsson N, Zetterberg H, Hansson O, et al. CSF biomarkers and incipient Alzheimer disease in patients with mild cognitive impairment. JAMA 2009;302:385-393.
15. Mattsson N, Insel PS, Donohue M, et al. Independent information from cerebrospinal fluid amyloid-beta and florbetapir imaging in Alzheimer's disease. Brain 2015;138: $772-783$.

16. Mattsson N, Andreasson U, Persson S, et al. The Alzheimer's Association external quality control program for cerebrospinal fluid biomarkers. Alzheimers Dement 2011; 7:386-395.

17. Klunk WE, Engler H, Nordberg A, et al. Imaging brain amyloid in Alzheimer's disease with Pittsburgh compound B. Ann Neurol 2004;55:306-319.

18. Klunk WE, Perani D. Amyloid and neurodegeneration: converging and diverging paths. Neurology 2013;81:1728-1729.

19. Johnson KA, Minoshima S, Bohnen NI, et al. Appropriate use criteria for amyloid PET: a report of the amyloid imaging task force, the society of nuclear medicine and molecular imaging, and the Alzheimer's association. Alzheimers Dement 2013;9:e-1-e-16.

20. Clark CM, Schneider JA, Bedell BJ, et al. Use of florbetapir-PET for imaging B-amyloid pathology. JAMA 2011;305:275-283.

21. Jack CR Jr, Knopman DS, Jagust WJ, et al. Hypothetical model of dynamic biomarkers of the Alzheimer's pathological cascade. Lancet Neurol 2010;9:119-128.

22. Jack CR Jr, Knopman DS, Jagust WJ, et al. Tracking pathophysiological processes in Alzheimer's disease: an updated hypothetical model of dynamic biomarkers. Lancet Neurol 2013;12:207-216.

23. Albert MS, DeKosky ST, Dickson D, et al. The diagnosis of mild cognitive impairment due to Alzheimer's disease: recommendations from the National Institute on Aging and Alzheimer's Association Workgroup. Alzheimers Dement 2011;7:270-279.

24. McKhann GM, Knopman DS, Chertkow H, et al. The diagnosis of dementia due to Alzheimer's disease: recommendations from the National Institute on Aging and the Alzheimer's Association workgroup. Alzheimers Dement 2011;7:263-269.

25. Jack CR Jr, Albert MS, Knopman DS, et al. Introduction to the recommendations from the National Institute on Aging-Alzheimer's Association workgroups on diagnostic guidelines for Alzheimer's disease. Alzheimers Dement 2011;7:257-262.

26. Sperling RA, Aisen PS, Beckett LA, et al. Toward defining the preclinical stages of Alzheimer's disease: recommendations from the National Institute on Aging-Alzheimer's Association workgroups on diagnostic guidelines for Alzheimer's disease. Alzheimers Dement 2011;7:280-292.

27. Petersen RC. Mild cognitive impairment as a diagnostic entity. J Intern Med 2004; 256:183-194.

28. Jack CR Jr, Wiste HJ, Weigand SD, et al. Amyloid-first and neurodegeneration-first profiles characterize incident amyloid PET positivity. Neurology 2013;81:1732-1740.

29. Jack CR Jr, Wiste HJ, Weigand SD, et al. Age-specific population frequencies of cerebral beta-amyloidosis and neurodegeneration among people with normal cognitive function aged 50-89 years: a cross-sectional study. Lancet Neurol 2014;13: 997-1005.

30. Petersen RC, Aisen P, Boeve BF, et al. Mild cognitive impairment due to Alzheimer disease in the community. Ann Neurol 2013;74:199-208.

31. Wolk DA, Price JC, Saxton JA, et al. Amyloid imaging in mild cognitive impairment subtypes. Ann Neurol 2009;65:557-568.

32. Prestia A, Caroli A, van der Flier WM, et al. Prediction of dementia in MCI patients based on core diagnostic markers for Alzheimer disease. Neurology 2013;80: 1048-1056.

33. Dubois B, Feldman HH, Jacova C, et al. Advancing research diagnostic criteria for Alzheimer's disease: the IWG-2 criteria. Lancet Neurol 2014;13:614-629.

34. Dubois B, Hampel H, Feldman HH, et al. Preclinical Alzheimer's disease: definition, natural history, and diagnostic criteria. Alzheimers Dement 2016;12:292-323.

35. Petersen RC, Caracciolo B, Brayne C, Gauthier S, Jelic V, Fratiglioni L. Mild cognitive impairment: a concept in evolution. J Intern Med 2014;275:214-228.

36. American Psychiatric Association. Diagnostic and Statistical Manual of Mental Disorders: DSM-5, 5th ed. Washington, DC: American Psychiatric Association; 2013.

37. Jack CR Jr, Carrillo MC, Ryan LM, Sperling R. 2017 NIA-AA research framework to investigate the Alzheimer's disease continuum. Alzheimer's Association International Conference (AAIC); London; July 16-20, 2017.

38. Jack CR, Bennett DA, Blennow K, et al. NIA-AA research framework: toward a biological definition of Alzheimer's disease. Alzheimers Dement 2018;14:535-562.

39. Sperling RA, Rentz DM, Johnson KA, et al. The A4 study: stopping AD before symptoms begin? Sci Transl Med 2014;6:228fs213.

40. Mormino EC, Betensky RA, Hedden T, et al. Synergistic effect of beta-amyloid and neurodegeneration on cognitive decline in clinically normal individuals. JAMA Neurol 2014;71:1379-1385.

41. Sperling RA, Karlawish J, Johnson KA. Preclinical Alzheimer disease: the challenges ahead. Nat Rev Neurol 2013;9:54-58.

42. Jessen F, Amariglio RE, van Boxtel M, et al. A conceptual framework for research on subjective cognitive decline in preclinical Alzheimer's disease. Alzheimers Dement 2014;10:844-852.

43. Molinuevo JL, Rabin LA, Amariglio R, et al. Implementation of subjective cognitive decline criteria in research studies. Alzheimers Dement 2017;13:296-311.

44. Kryscio RJ, Abner EL, Cooper GE, et al. Self-reported memory complaints: implications from a longitudinal cohort with autopsies. Neurology 2014;83:1359-1365.

45. Van Harten AC, Mielke MM, Swenson-Dravis DM, et al. Subjective cognitive decline and risk of MCI: the Mayo Clinic Study of Aging. Neurology Epub 2018 Jun 29.

46. Amariglio RE, Townsend MK, Grodstein F, Sperling RA, Rentz DM. Specific subjective memory complaints in older persons may indicate poor cognitive function. J Am Geriatr Soc 2011;59:1612-1617.

47. Schneider JA, Arvanitakis Z, Bang W, Bennett DA. Mixed brain pathologies account for most dementia cases in community-dwelling older persons. Neurology 2007;69: 2197-2204. 
48. Beach TG, Monsell SE, Phillips LE, Kukull W. Accuracy of the clinical diagnosis of Alzheimer disease at National Institute on Aging Alzheimer disease centers, 20052010. J Neuropathol Exp Neurol 2012;71:266-273.

49. Rabinovici GD, Carrillo MC, Forman M, et al. Multiple comorbid neuropathologies in the setting of Alzheimer's disease neuropathology and implications for drug development. Alzheimers Dement 2017;3:83-91.

50. Jack CR Jr, Therneau TM, Wiste HJ, et al. Transition rates between amyloid and neurodegeneration biomarker states and to dementia: a population-based, longitudinal cohort study. Lancet Neurol 2016;15:56-64.

51. Jack CR, Wiste HJ, Weigand SD, et al. Defining imaging biomarker cut points for brain aging and Alzheimer's disease. Alzheimers Dement 2017;13:205-216.

52. Josephs KA, Whitwell JL, Weigand SD, et al. TDP-43 is a key player in the clinical features associated with Alzheimer's disease. Acta Neuropathol 2014;127: $811-824$.
53. Uchikado H, Lin WL, DeLucia MW, Dickson DW. Alzheimer disease with amygdala Lewy bodies: a distinct form of alpha-synucleinopathy. J Neuropathol Exp Neurol 2006;65:685-697.

54. Schneider JA, Boyle PA, Arvanitakis Z, Bienias JL, Bennett DA. Subcortical infarcts, Alzheimer's disease pathology, and memory function in older persons. Ann Neurol 2007;62:59-66.

55. DeCarli C, Miller BL, Swan GE, Reed T, Wolf PA, Carmelli D. Cerebrovascular and brain morphologic correlates of mild cognitive impairment in the national heart, lung, and blood Institute twin study. Arch Neurol 2001;58:643-647.

56. Smith EE, Schneider JA, Wardlaw JM, Greenberg SM. Cerebral microinfarcts: the invisible lesions. Lancet Neurol 2012;11:272-282.

57. Petersen RC, Lopez O, Armstrong MJ, et al. Practice guideline update: mild cognitive impairment: report of the Guideline Development, Dissemination, and Implementation Subcommittee of the American Academy of Neurology. Neurology 2018;90:126-135.

\section{A New Generation of Fall Conference}

Register today for the 2018 Fall Conference taking place October 26 through 28 in Las Vegas and experience an enhanced and expanded program complete with some of the most popular education courses and breakthrough scientific research from the record-setting 2018 Annual Meeting.

Visit AAN.com/view/fall today.

\section{Share Your Artistic Expressions in Neurology 'Visions'}

AAN members are urged to submit medically or scientifically related artistic images, such as photographs, photomicrographs, and paintings, to the "Visions" section of Neurology ${ }^{\odot}$. These images are creative in nature, rather than the medically instructive images published in the NeuroImages section. The image or series of up to six images may be black and white or color and must fit into one published journal page. Accompanying description should be 100 words or less; the title should be a maximum of 96 characters including spaces and punctuation.

Please access the Author Center at NPub.org/authors for full submission information.

\section{The AAN Has Your Back!}

Every day, the AAN is fighting for you. From actively lobbying members of Congress for common sense legislation, to meeting with regulators to demonstrate the value of neurology and reduce regulatory hassles, the Academy is forcefully countering any threats to your profession and patient access to care. Learn more at AAN.com/policy-and-guidelines/advocacy, read the bimonthly Capitol Hill Report and monthly AANnews member magazine, and respond to Advocacy Action Alert emails when we invite you to share your voice with Congress.

Get into the conversation at \#AANAdvocacy. 


\section{Neurology}

How early can we diagnose Alzheimer disease (and is it sufficient)?: The 2017 Wartenberg lecture

Ronald C. Petersen

Neurology 2018;91;395-402 Published Online before print August 8, 2018

DOI 10.1212/WNL.0000000000006088

This information is current as of August 8, 2018

Neurology ${ }^{\circledR}$ is the official journal of the American Academy of Neurology. Published continuously since 1951, it is now a weekly with 48 issues per year. Copyright Copyright $@ 2018$ The Author(s). Published by Wolters Kluwer Health, Inc. on behalf of the American Academy of Neurology.. All rights reserved. Print ISSN: 0028-3878. Online ISSN: 1526-632X.

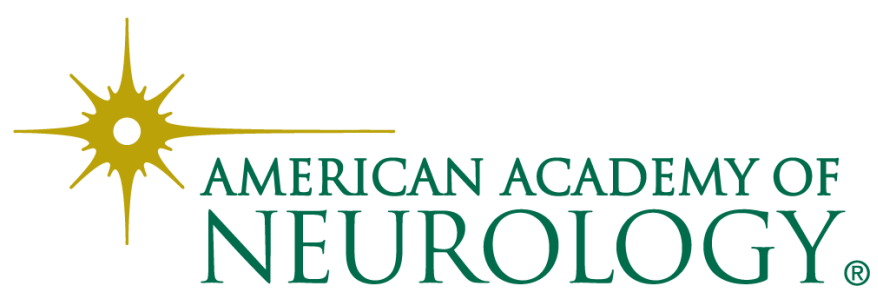




\section{Updated Information \& Services}

\section{Supplementary Material}

\section{References}

Citations

Subspecialty Collections

Permissions \& Licensing

\section{Reprints}

including high resolution figures, can be found at: http://n.neurology.org/content/91/9/395.full

Supplementary material can be found at: http://n.neurology.org/content/suppl/2018/08/27/WNL.0000000000006 088.DC1

This article cites 54 articles, 8 of which you can access for free at: http://n.neurology.org/content/91/9/395.full\#ref-list-1

This article has been cited by 2 HighWire-hosted articles: http://n.neurology.org/content/91/9/395.full\#\#otherarticles

This article, along with others on similar topics, appears in the following collection(s):

Alzheimer's disease

http://n.neurology.org/cgi/collection/alzheimers_disease

Cerebrospinal Fluid

http://n.neurology.org/cgi/collection/cerebrospinal_fluid

MCI (mild cognitive impairment)

http://n.neurology.org/cgi/collection/mci_mild_cognitive_impairment

\section{MRI}

http://n.neurology.org/cgi/collection/mri

PET

http://n.neurology.org/cgi/collection/pet

Information about reproducing this article in parts (figures,tables) or in its entirety can be found online at:

http://www.neurology.org/about/about_the_journal\#permissions

Information about ordering reprints can be found online:

http://n.neurology.org/subscribers/advertise

Neurology ${ }^{\circledR}$ is the official journal of the American Academy of Neurology. Published continuously since 1951, it is now a weekly with 48 issues per year. Copyright Copyright ( 2018 The Author(s). Published by Wolters Kluwer Health, Inc. on behalf of the American Academy of Neurology.. All rights reserved. Print ISSN: 0028-3878. Online ISSN: 1526-632X.

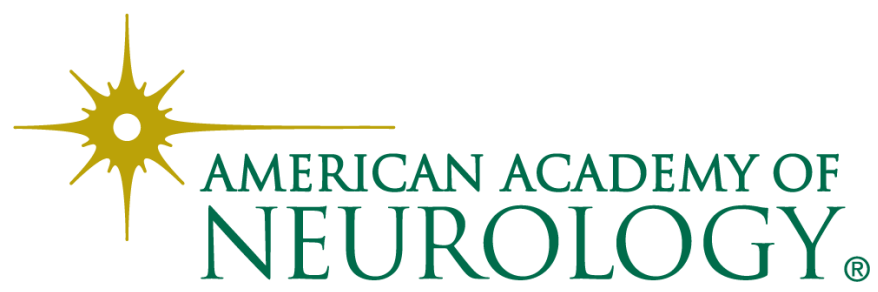

